\title{
Motivation and Factors Affecting It among Health Professionals in the Public Hospitals, Central Ethiopia
}

\author{
Tesfaye Dagne ${ }^{1}$, Waju Beyene ${ }^{2}$, Negalign Berhanu ${ }^{2}$
}

\section{ABSTRACT}

BACKGROUND: Motivation is an individual's degree of willingness to exert and maintain an effort towards organizational goals. This study assessed motivational status and factors affecting it among health professionals in public hospitals of West Shoa Zone, Oromia Region.

METHOD: Facility based cross-sectional survey was employed. All health professionals who served at least for 6 months in Ambo, Gedo and Gindeberet hospitals were included. Self-administered Likert scale type questionnaire was used. Data were analyzed using SPSS version 20. Mean motivation calculated as percentage of maximum scale score was used. Bivariate and multiple linear regression analyses were done to see the independent effects of explanatory variables.

RESULTS: The overall motivation level of health professionals was 63.63\%. Motivation level of health professionals varied among the hospitals. Gindeberet Hospital had lower motivation score as compared to Ambo Hospital $(B=-0.54$ and 95\% CI; -0.08,-0.27). The mean motivation score of health professionals who got monthly financial benefit was significantly higher than those who did not $(B=0.71$ and $95 \%$ CI; 0.32, 1.10). Environmental factors had higher impact on doctors' motivation compared to nurses' $(B=0.51$ and $95 \% C I ; 0.10,0.92)$. Supervisor-related factors highly varied in motivation relative to other variables.

CONCLUSIONS: Motivation of health professionals was affected by factors related to supervisor, financial benefits, job content and hospital location. Efforts should be made to provide financial benefits to health professionals as appropriate especially, to those who did not get any such benefits. Officially recognizing best performance is also suggested.

KEYWORDS: Motivation, Health Professionals, West Shoa, Hospital, Oromia, Ethiopia

DOI: http://dx.doi.org/10.4314/ejhs.v25i3.6

\section{INTRODUCTION}

Motivation in the work context can be defined as an individual's degree of willingness to exert and maintain an effort towards organizational goals. Work motivation is an internal process in which an individual receives certain stimulus from the environment (rewards, feedback, directives and consequences of previous efforts) which combine with certain internal features (self-concept and needs) (1).

Policy makers are becoming aware of health workers' motivation and its importance in performances of healthcare system. Healthcare system requires high labor and delivery of service quality, efficiency and equity, which are dependent on health workers' motivation to exert their effort on their tasks. Although availability of resources and skills of health workers are important, health managers and decision makers should know that these factors are not enough by themselves to make health workers work to the expected level of performance that is influenced by their willingness to come to work regularly, work diligently and be flexible and willing to carry out the necessary tasks (2).

\footnotetext{
${ }^{1}$ Department of Health Service Management, Jimma University, Ethiopia

${ }^{2}$ Shashemene Town Health Office, Oromiya, Ethiopia

Corresponding Author: Negaligh Berhanu, Email: negenu@gmail.com
} 
Poor health systems, with lack of equipment, supplies and poor management structures, lead to poor productivity, limited competences and poor responsiveness. The root causes that result in suboptimal performance in these areas consist of a complex set of factors, which are interrelated. These include the complexity and challenges involved in providing and managing competing demands in patient care, which can contribute to job dissatisfaction and low motivation among health care professionals $(3,4)$.

In developing countries, low staff motivation and shortage of human resources for health $(\mathrm{HRH})$ are factors that are crippling health systems and health care. Despite this, the development of human resources has been given little attention at global and national levels until recently. Effective health service delivery requires efficient use of the skills of a wellmotivated health workforce. The delivery of care by its nature involves personal interaction and effective teamwork. Improving staff motivation and performance through effective use of pay and non-pay incentives such as the provision of education and career development opportunities, flexibility in working schedules, safe working environments and other factors is an important issue in health services provision $(5,6)$.

In Ethiopia, manpower in the health service is small, unevenly distribution, underutilized in some cases, and does not have the appropriate level and mix of skills. An appropriate system of supervision and monitoring is also lacking. Performance and standards have been insufficient, particularly due to lack of appropriate career structure and incentive schemes. Management at all levels of the health care delivery system appears to be headed by health professionals who neither have the training nor the motivation. The attrition, under current conditions, is expected to be particularly high for physicians, health officers and pharmacists. This indicates the urgency to develop human resource management system and policy in order to retain a motivated health workforce $(7,8)$.

Results from a qualitative study on performance of health workers in Ethiopia (9) revealed poor treatment or inadequate service in health institutions. Health workers in public facilities are often absent during working hours, or they simply "sit around" while patients are waiting, and these complaints are acknowledged by health workers. However, the real causes are inadequate facilities and lack of material, which are seen as being beyond the control of health professionals. This is a source of frustration for many health workers and affects their motivation, which in turn affects their performance. Many feel that a career in the health sector has become less attractive. These frustrations are rooted in a number of more specific complaints. Thus, this study was conducted to identify the level of motivation and factors affecting it among health professionals in the study area to provide evidences for responsible bodies for making improvement decisions.

\section{METHODS AND MATERIALS}

The study was conducted in West Shoa Zone, one of the 18 zones in Oromia Regional State, Central Ethiopia, from February 15, 2013 to March 30, 2013. West Shoa Zone has 19 Woredas (18 rural and one urban) and three public hospitals: Ambo, Gedo and Gindeberet hospitals with a total of 103, 51 and 72 health professionals, respectively. Both Gindeberet and Gedo hospitals are district hospitals and Ambo hospital is a General hospital by type.

Facility based cross-sectional study design was employed using both quantitative and qualitative methods. Since the number of health professionals working in the three public hospitals was manageable for the study, all permanently employed health professionals who served for more than 6 months in their respective hospitals were included in the study. Health professionals with work experiences of less than six months were excluded because these health professionals had not faced the true situation of the hospital environment, and the first six month for newly employed health professionals were considered as a trial period.

Quantitative data were collected using a self-administered questionnaire adapted from different literatures (10-14). The questionnaire contained items categorized in to three, that is, socio-demographic characteristics of the respondents, their motivational status and factors affecting their motivation, with responses in five label Likert scale (Strongly disagree $=1$; Disagree $=2 ;$ Neutral $=3 ;$ Agree $=4$ and 
strongly agree $=5$ ). The questionnaire was prepared in English. It was distributed and collected back by three data collectors.

Qualitative data were collected through in-depth interviews. A total of six key informants were involved that included clinical directors and chief executive officers of the respective hospitals. Notes were taken and each interview was tape-recorded. The interview guide focused on systems and strategies each hospital was implementing to motivate its employees, general perception of motivational status of health professionals, and what the interviewees recommend for the health system to motivate health professionals. The data obtained through qualitative method were triangulated with the quantitative ones. while motivation, which is a composite variable consisting of 12 items, measured on five likert scale, was the dependent variable. The independent variables included sociodemographic characteristics of the respondents (age, sex, marital status, ethnicity, education, work experience, profession, qualification and salary); work environment (physical conditions, supplies, chance for creativity, hospital location and policy); benefit-related factors (additional income and employment benefits); job-related factors (training opportunities, job security, working relationships and nature of work); and supervisor-related factors (relation with supervisor and Supervisor's recognition and appreciation).

Quantitative data were entered into computer and analyzed using SPSS for window version 20.0. Factor analysis was employed for all Likert scale instruments to extract factors representing each of the scales and had factor scores. Kaiser-Meyer-Olkin (KMO> 0.5) Measure of Sampling Adequacy and Bartlett's Test of Significance (0.000) were used to test suitability of the data to factor analysis. Principal axis factoring with Eigen value greater than or equal to one extraction and varimax rotation methods were employed. This facilitated treatment of the variables as continuous in further analyses. Bivariate (correlation) analyses were used to assess the relationships between independent and dependent variables, and ANOVA was used, after checking for assumptions, to show whether the difference in mean motivation level between different group was statistically significant or not. Then, multiple linear regression analysis was employed to identify the predictors of motivation of health professionals. Variables that were found to be significant at 0.20 or less level of significance by bivariate analysis were entered into the multivariate analysis to rule out confounders. Mean score of the respondents calculated as percentage of maximum scale score was used for measuring level of motivation of health professionals. This calculation was made with the Likert scales before factors were generated. The findings were presented in tables and figures.

Efforts were made to ensure quality of the data. Training was given to data collectors for one day on the contents of the questionnaire and process of data collection. The questionnaire was pretested at Bishoftu Hospital by taking 10\% of sample size a week prior to the actual study and slight modification was made. Close supervision was carried out on daily basis by the principal investigator, and the questionnaires were checked for missing values and inconsistencies.

Ethical clearance was obtained from the Ethical Review Committee of the College of Public Health and Medical Sciences, Jimma University. A letter of cooperation was written to West Shoa Zonal Health Department and to the respective study hospitals. Informed oral consent was obtained from each respondent during data collection.

\section{RESULTS}

Socio-demographic characteristics: In total, 217 health professionals participated in this study from the three hospitals making the response rate $96.02 \%$. The median age of the respondents was 26 years with a range of 20-57 years. Oromo ethnicity accounted for more than $83 \%$ of the study participants. More than $55 \%$ of the health professionals were protestant religion followers. More than half $(51.6 \%)$ of the respondents were single and about $53 \%$ of them were diploma holders. The median monthly salary of the respondents was 1881.00 ETB with a range of 1000.00-4,343.00 ETB. Seventy-two percent of the 
participants were not getting any type of monthly allowances other than their salaries (Table 1).

Table 1: Socio-demographic characteristics of respondents, West Shoa Zone, Oromia Region, Central Ethiopia, March 2013

\begin{tabular}{|c|c|c|c|}
\hline Variables $(\mathrm{N}=217)$ & Categories & Frequency & Percent \\
\hline \multirow{4}{*}{ Age } & $20-24$ & 56 & 25.8 \\
\hline & $25-29$ & 112 & 51.6 \\
\hline & $30-34$ & 28 & 12.9 \\
\hline & $>=35$ & 21 & 9.7 \\
\hline \multirow[t]{2}{*}{ Sex } & Male & 113 & 52.1 \\
\hline & Female & 104 & 47.9 \\
\hline \multirow[t]{4}{*}{ Ethnicity } & Oromo & 182 & 83.9 \\
\hline & Amhara & 21 & 9.7 \\
\hline & Tigre & 5 & 2.3 \\
\hline & Others & 9 & 4.1 \\
\hline \multirow[t]{4}{*}{ Religion } & Orthodox & 76 & 35.0 \\
\hline & Protestant & 120 & 55.3 \\
\hline & Muslim & 17 & 7.8 \\
\hline & Others & 4 & 1.8 \\
\hline \multirow[t]{2}{*}{ Marital status } & Single & 112 & 51.6 \\
\hline & Married & 105 & 48.4 \\
\hline \multirow{4}{*}{$\begin{array}{l}\text { Healthcare work } \\
\text { experiences }\end{array}$} & $<=4.9$ & 116 & 53.5 \\
\hline & $5-9.9$ & 68 & 31.3 \\
\hline & $10-14.9$ & 18 & 8.3 \\
\hline & $>=15$ & 15 & 6.9 \\
\hline \multirow[t]{3}{*}{ Qualification } & Diploma & 113 & 52.1 \\
\hline & BSc degree & 99 & 45.6 \\
\hline & Masters degree & 5 & 2.3 \\
\hline \multirow[t]{4}{*}{ Monthly salary } & $<=1233$ & 32 & 14.7 \\
\hline & $1234-2249$ & 87 & 40.1 \\
\hline & $2250-3413$ & 78 & 35.9 \\
\hline & $>=3414$ & 20 & 9.2 \\
\hline \multirow{4}{*}{$\begin{array}{l}\text { Monthly financial } \\
\text { allowance }\end{array}$} & 0 & 156 & 71.9 \\
\hline & $1-499$ & 28 & 12.9 \\
\hline & $500-999$ & 18 & 8.3 \\
\hline & $>=1000$ & 15 & 6.9 \\
\hline
\end{tabular}

The majority (44\%) of the study participants were nurses followed by medical doctors $(11 \%)$ and laboratory professionals (9\%), among others. Work experience varied from 4 years to more than 15 years. Most experienced health professionals (15 years or more) were more present at Ambo Hospital, and less experienced health professionals (less than 5) were more present at Gindeberet Hospital (Figure 1). 


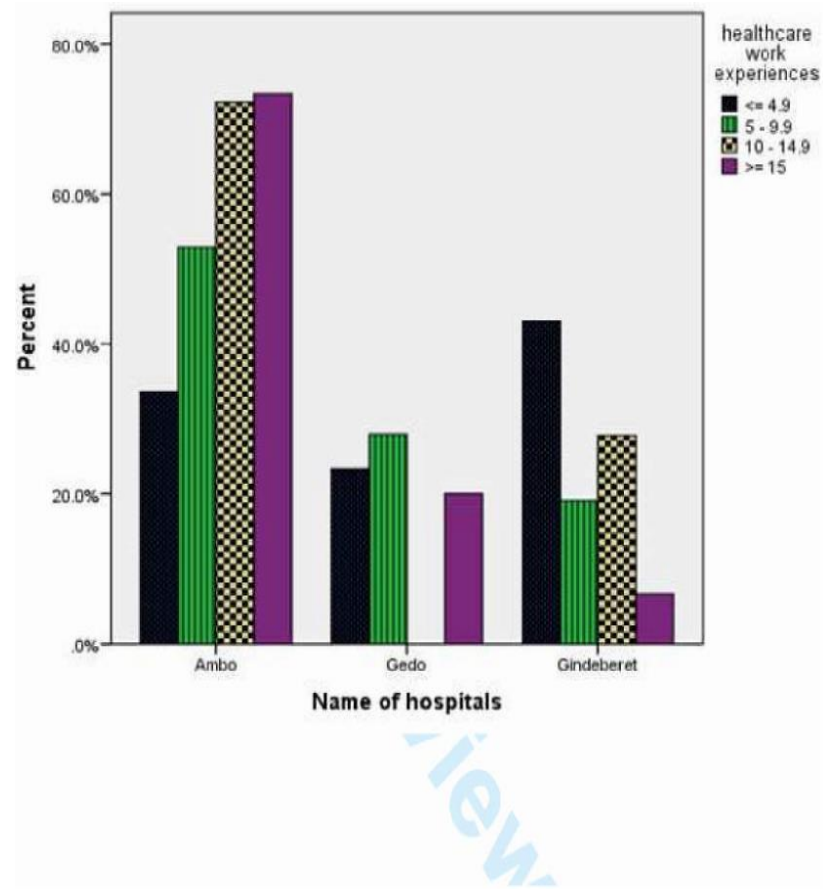

Figure 1: Work experience of health professionals by hospital, West Shoa Zone, Oromia Region, Central Ethiopia, March 2013

Motivational status: The mean motivation score was highest in Ambo Hospital $(72.52 \%)$ and lowest in Gindebert Hospital $(49.46 \%)$. An in-depth interview participant also supported this idea saying: "But this people according to our district, for example, water supply and electricity services will be interrupted frequently; they do not obtain transportation services when they need it, there is absolutely no recreation center which disappoints them" (39 years old, CEO). Male health professionals had relatively higher mean motivation score $(67.10 \%)$ than their female counterparts $(59.86 \%)$. Health professionals who worked for less than five years and those who were Protestant had the least mean motivation scores, $(60.56 \%)$ and $(61.91 \%)$, respectively. Health professionals with Master's degree and doctors (Medical doctors and Dental doctors) had the highest mean motivation scores, (95.00\%) and $93.50 \%)$, respectively. As we move from the lowest to the highest monthly allowance scale of the health professionals, their mean motivation scores increase sharply with increment in amount of any type of monthly allowances (Table 2).

Fifty-seven point three percent of the health professionals showed a mean motivation score of greater than $50 \%$, while a significant proportion $(21.2 \%)$ had a mean motivation score of less than $25 \%$ as calculated by percentage of maximum possible scale. The overall mean motivation score of health professionals was found to be $63.63 \%$ (Figure 2). On the other hand, all the in-depth interview participants rated the motivation status of their respective health professionals as "medium". 
Table 2: Mean motivation score of health professionals versus socio-demographic characterstics in West Shoa zone, Oromia region, central Ethiopia, March 2013

\begin{tabular}{|c|c|c|c|c|}
\hline \multicolumn{2}{|l|}{ Variables $(\mathrm{N}=\mathbf{2 1 7})$} & \multirow{2}{*}{$\begin{array}{l}N \\
99\end{array}$} & \multirow{2}{*}{$\begin{array}{l}\text { \% Mean (Total mean } \\
\text { 63.63\%) } \\
72.52\end{array}$} & \multirow{2}{*}{$\begin{array}{l}\text { Std. Deviation (total std. } \\
\text { dev 34.99) } \\
27.94\end{array}$} \\
\hline Name of hospitals & Ambo & & & \\
\hline & Gedo & 49 & 65.64 & 33.68 \\
\hline & Gindeberet & 69 & 49.46 & 40.52 \\
\hline \multirow[t]{4}{*}{ Age (in years) } & $20-24$ & 56 & 59.44 & 32.32 \\
\hline & $25-29$ & 112 & 61.38 & 37.56 \\
\hline & $30-34$ & 28 & 77.23 & 26.65 \\
\hline & $>=35$ & 21 & 68.65 & 34.63 \\
\hline \multirow[t]{2}{*}{ Sex } & male & 113 & 67.10 & 33.64 \\
\hline & female & 104 & 59.86 & 36.18 \\
\hline \multirow[t]{4}{*}{ Ethnicity } & Oromo & 182 & 62.34 & 35.51 \\
\hline & Amhara & 21 & 67.66 & 35.91 \\
\hline & Tigre & 5 & 65.83 & 37.08 \\
\hline & Others* & 9 & 79.17 & 16.00 \\
\hline \multirow[t]{4}{*}{ Religion } & Orthodox & 76 & 65.57 & 36.75 \\
\hline & Protestant & 120 & 61.91 & 34.83 \\
\hline & Muslim & 17 & 63.48 & 32.06 \\
\hline & Others** & 4 & 79.17 & 16.32 \\
\hline \multirow[t]{2}{*}{ Marital status } & Single & 112 & 61.42 & 33.98 \\
\hline & Married & 105 & 65.99 & 36.05 \\
\hline healthcare & $<=4.9$ & 116 & 60.56 & 35.37 \\
\hline experiences & $5-9.9$ & 68 & 64.03 & 34.67 \\
\hline \multirow[t]{2}{*}{ years) } & $10-14.9$ & 18 & 77.54 & 29.91 \\
\hline & $>=15$ & 15 & 68.89 & 37.66 \\
\hline \multirow[t]{3}{*}{ qualification } & Diploma & 113 & 60.17 & 34.01 \\
\hline & BSc degree & 99 & 65.99 & 36.08 \\
\hline & Masters degree & 5 & 95.00 & 11.18 \\
\hline \multirow[t]{5}{*}{ profession } & Nurse & 95 & 59.08 & 35.07 \\
\hline & Laboratory & 19 & 68.20 & 28.64 \\
\hline & MD/DDM & 25 & 93.50 & 11.54 \\
\hline & Pharmacy & 15 & 69.72 & 35.96 \\
\hline & Others*** & 63 & 55.82 & 36.74 \\
\hline monthly & $<=1233$ & 32 & 63.67 & 30.06 \\
\hline \multirow[t]{3}{*}{ (ETB) } & $1234-2249$ & 87 & 60.30 & 34.33 \\
\hline & $2250-3413$ & 78 & 59.72 & 38.20 \\
\hline & $>=3414$ & 20 & 93.33 & 12.41 \\
\hline monthly allowances & 0.00 & 156 & 55.87 & 34.30 \\
\hline \multirow[t]{3}{*}{ (ETB) } & $150-499$ & 28 & 70.69 & 36.87 \\
\hline & 500-999 & 18 & 93.28 & 10.99 \\
\hline & $>=1000$ & 15 & 95.56 & 10.26 \\
\hline \multirow{2}{*}{$\begin{array}{l}\text { monthly financial } \\
\text { benefits(ETB) }\end{array}$} & 0.00 & 196 & 60.31 & 35.12 \\
\hline & $>=200.00$ & 21 & 94.64 & 8.85 \\
\hline
\end{tabular}

$\mathrm{N}=$ number (frequencies) Others $*=$ Gurage, Kambata, Wolaita. Others** $=$ Wakefata, Catholic, Adventist Others $* * *=$ Radiology, Physiotherapy, Environmental health, Anesthesia, Health officer 


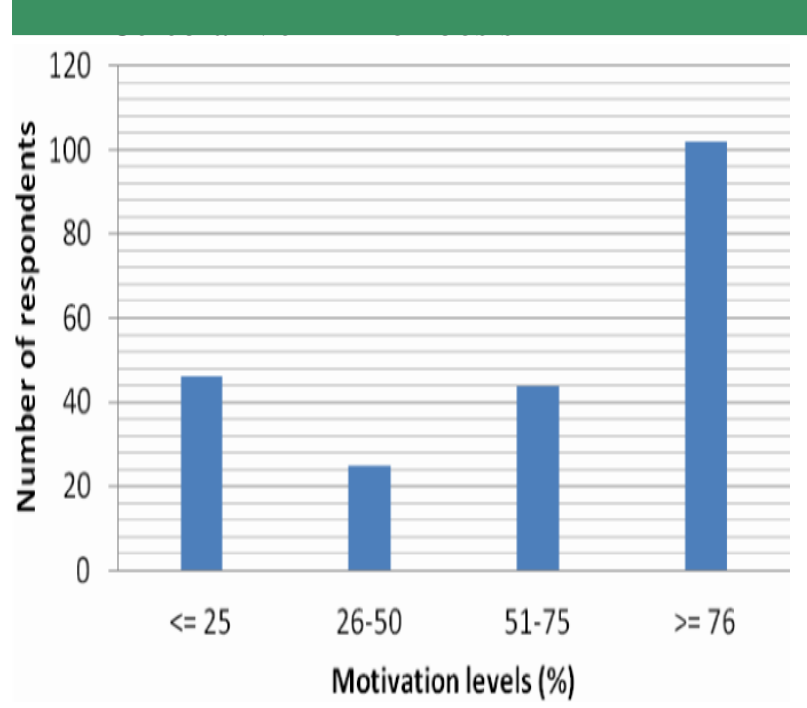

Figure 2: Mean motivation score level of health professionals in West Shoa Zone, Oromoa Region, central Ethiopia, March 2013

For the determination of factors affecting motivation of health professionals, the data were subjected to factor analysis to identify the fewest number of factors that can represent the areas covered by the items. After factor analysis, one factor consisting of six items (out of 12) explaining $81.50 \%$ of the variability was extracted for motivation questions. Similarly, job content, work environment, benefit and supervisor related factors had undergone factor analysis. The job content factor included 5 items and one factor consisting of 4 items and explaining $65.32 \%$ of variability was extracted. For work environment, all the items (four of them) were included in one factor explaining for $67.85 \%$ of the variability. Four from the five items were extracted as one factor from the benefitrelated factors explaining $69.51 \%$ of the variability. The supervisor related factor included all the items in one factor explaining for $75.02 \%$ of the variability. Since all of these factors contain only one factor identified for each category based on their Eigen value, communality, factor loading and the total variance explained, their names were retained as original name.

Bivariate analysis of the factors that affect motivation revealed that age, work experiences and monthly allowances were correlated with motivation of health professionals at significance level of 0.20 . All other factors affecting motivation (job content, work environment, benefits and supervisor related factors) were correlated at the significance level of $<0.01$ (Table 3). The importance of financial incentives as a motivator was also stressed by in-depth interview participants. For instance, a 27 years old clinical director said, "Our hospital provides 700.00 Ethiopian birr incentives per month for each medical doctor on top of the allowance given to them from the regional government." "We emphasize on financial incentives because it is important for retaining higher health professionals" (A 50 years old CEO).

Bivariate analysis (correlation) of sociodemographic variables and motivation of health professionals showed that qualification, profession and hospital location were associated with motivation at significance level of $<0.20$. Since monthly salary and qualification of health professionals were found to have multi-co linearity, monthly salary was excluded from the analysis.

According to the stepwise regression analysis, job content related motivation was affected by qualification, hospital location and monthly allowances. Job content was 0.43 units more important in motivating BSC degree holders when compared with its effect on diploma holders $(B=$ 0.43 and $95 \%$ CI; 0.17, 0.69). On the other hand, health professionals working at Gedo Hospital responded that the gepgraphical location of their hospital is 0.44 units less important in motivating them when compared with their counterparts working at Ambo Hospital $(B=-0.44$ and $95 \%$ CI; -0.74, -0.13). Similarly, health professionals who had been earning monthly financial allowances of 500-999 ETB responded that the allowance is 0.63 units more important in motivating them when compared to those earning below 500 or above 999 ETB $(B=0.63$ and $95 \% \mathrm{CI}$; 0.17, 1.09). In-depth interview participants supported this idea as: "Health professionals who obtain incentives are more motivated than those who do not obtain incentives." (27 years old, clinical director) "But there is something that these health professionals need, meaning additional things that motivate them. For example nurses are obtaining 35.00 Ethiopian birr duties. They need this duty to be increased. There is also a question for salary increase." (26 years old, clinical director)

Motivational value of work environment varied from profession to profession. Accordingly, 
medical doctor and doctor of dental medicine assumed work environment as 0.51 units more important in motivating them when compared with nurses ( $B=0.51$ and $95 \% C I ; 0.10,0.92)$. And, health professionals working at Gindeberet Hospital responded that work environment is about 0.38 units less important in motivating them when compared with health professionals working at Ambo Hospital $(B=-0.38$ and $95 \%$ CI; -0.66, 0.11). Similarly, Orthodox Christianity followers (0.30 units and BSc degree holders (0.29 units) responded that work environment is more important in motivating them: $(B=0.30$ and $95 \% \mathrm{CI} ; 0.03,0.57)$ and $(B=0.29$ and $95 \%$ CI; 0.03, 0.55), respectively.

The role of supervision in motivating health professionals varied across level of qualification, religion and location of a hospital. In this regard, medical doctors and doctors of dental medicine rated supervisor related factors as 0.62 units more important when compared with nurses ( $B=0.62$ and 95\% CI; 0.22, 1.03). It was also about 0.96 units less important at Gindeberet Hospital when compared with health professionals working at Ambo Hospital $(B=-0.96$ and $95 \% \mathrm{CI} ;-1.23,-0.69)$. In addition, it was about 0.30 units more important for Orthodox Christianity followers as compared to followers of the protestant religion $(B=030$ and $95 \% \mathrm{CI} ; 0.06,055)$.

Hospital location, qualification and profession were factors that were found to affect benefit factors of motivation. For health professionals working at Gedo and Gindeberet hospitals benefit-related factors were 0.54 and 0.76 units less important in motivating them when compared with health professionals working at Ambo Hospital, $(B=-0.54$ and $95 \%$ $\mathrm{CI} ;-0.85,-0.22)$ and $(B=-76$ and $95 \% \mathrm{CI} ;-1.05$, -0.48), respectively. For laboratory professionals and doctor of dental medicine and medical doctor health professionals, benefit related factors were about 0.51 and 0.85 units more important in motivating them when compared with nursing health professionals $(B=0.51$ and $95 \% \mathrm{CI}$; $0.07,0.94)$ and $(B=0.85$ and $95 \% \mathrm{CI} ; 0.43$, $1.27)$, respectively.

Table 3: Bivariate analysis of factors affecting motivation among health professionals in West Shoa Zone, Oromia Region, Central Ethiopia, 2013

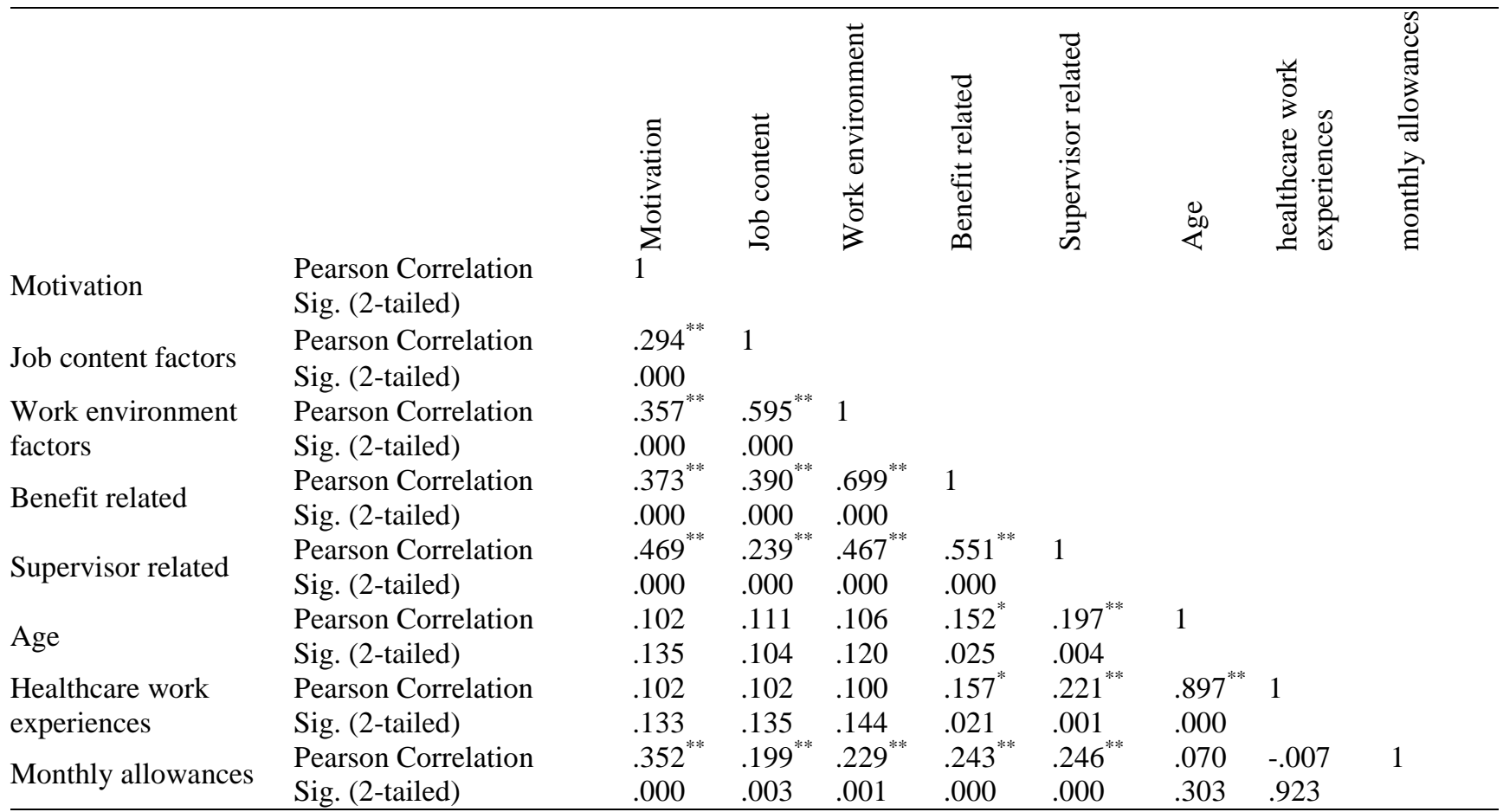

\begin{tabular}{|c|c|c|c|c|c|c|c|}
\hline 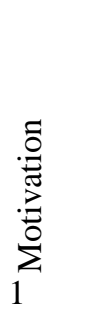 & 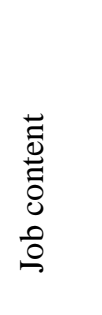 & 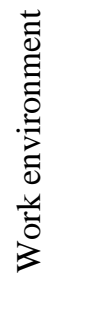 & 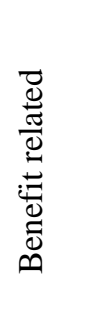 & 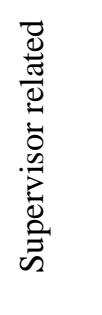 & $\underset{\pi}{\infty}$ & 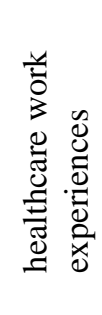 & 2 \\
\hline $.294^{* *}$ & 1 & & & & & & \\
\hline .000 & & & & & & & \\
\hline $.357^{* *}$ & $.595^{* *}$ & 1 & & & & & \\
\hline .000 & .000 & & & & & & \\
\hline $.373^{* *}$ & $.390^{* *}$ & $.699^{* *}$ & 1 & & & & \\
\hline .000 & .000 & .000 & & & & & \\
\hline $.469^{* *}$ & $.239^{* *}$ & $.467^{* *}$ & $.551^{* *}$ & 1 & & & \\
\hline .000 & .000 & .000 & .000 & & & & \\
\hline .102 & .111 & .106 & $.152^{*}$ & $.197^{* *}$ & 1 & & \\
\hline .135 & .104 & .120 & .025 & .004 & & & \\
\hline .102 & .102 & .100 & $.157^{*}$ & $.221^{* *}$ & $.897^{* *}$ & 1 & \\
\hline .133 & .135 & .144 & .021 & .001 & .000 & & \\
\hline $.352^{* *}$ & $.199^{* *}$ & $.229^{* *}$ & $.243^{* *}$ & $.246^{* *}$ & .070 & -.007 & 1 \\
\hline .000 & .003 & .001 & .000 & .000 & .303 & .923 & \\
\hline
\end{tabular}


Variables that had association by bivariate analysis at significance level of 0.20 or less were entered into the multivariate analysis. The multiple regression analysis showed that motivation of health professionals was associated with supervision, type of profession, job content, location of the hospital, and financial benefits. Accordingly, health professionals working at Gindeberet Hospital had about 0.54 units lower motivation score when compared with health professionals working at Ambo Hospital $(B=-0.54$ and 95\% CI; -0.80, -0.27) and professionals earning monthly benefits of 499 ETB and above had about 0.83 unit higher motivation score when compared with health professionals who did not obtain any financial benefits $(B=0.83$ and $95 \% \mathrm{CI} ; 0.39,1.27)$ (Table $4 \& 5$ ).

This is supported by in-depth interviews. For instance, a 26 years old clinical director said, “... but health professionals want additional money to their salaries in order to be motivated. For example nurses are getting 35.00 Ethiopian Birr per day for duty compensation, but they want this to be improved. Another group has no such benefits and thus are requesting for it. So everybody has his/her own question."

Table 4: Stepwise multiple regression analysis showing the final model of factors affecting motivation of health professionals in West Shoa Zone, Oromia region, Central Ethiopia, 2013

\begin{tabular}{llllll}
\hline Model & \multicolumn{2}{l}{ Unstandardized } & Standardized & Sig. & $95 \%$ CI \\
& \multicolumn{2}{l}{ Coefficients } & Coefficients & & \\
& B & Std. Error & Beta & & \\
(Constant) & .010 & .073 & & .887 & $-.133, .153$ \\
Supervisor related factor & .287 & .064 & .287 & .000 & $.162, .412$ \\
Medical doctor \& doctor of dental medicine & .596 & .182 & .191 & .001 & $.237, .955$ \\
Job content factor & .213 & .059 & .213 & .000 & $.097, .330$ \\
Gindeberet hospital & -.424 & .132 & -.198 & .002 & $-.684,-.164$ \\
Benefits less than 499 & 1.012 & .338 & .166 & .003 & $.345,1.679$ \\
Benefits of 500-999 & .670 & .285 & .134 & .020 & $.108,1.231$
\end{tabular}

Dependent variable: work motivation

Table 5: Stepwise multiple regression analysis of results of factors affecting motivation of health professionals, West Shoa zone, Oromia region, central Ethiopia, March 2013

\begin{tabular}{|c|c|c|c|c|c|c|c|}
\hline \multirow[t]{2}{*}{ Model } & \multirow[t]{2}{*}{$\mathrm{F}(\%)$} & \multicolumn{2}{|c|}{$\begin{array}{l}\text { Unstandardized } \\
\text { Coefficients }\end{array}$} & \multirow{2}{*}{$\begin{array}{c}\text { Standardized } \\
\text { Coefficients } \\
\text { Beta } \\
\end{array}$} & \multirow[t]{2}{*}{ Sig. } & \multicolumn{2}{|c|}{$95.0 \%$ Confidence Interval for B } \\
\hline & & B & Std. Error & & & Lower Bound & Upper Bound \\
\hline Benefits & & & & & & & \\
\hline No benefit* & 196(90.3) & - & - & - & - & - & - \\
\hline$>=200 \mathrm{ETB}$ & $21(9.7)$ & .71 & .20 & .21 & .000 & .32 & 1.10 \\
\hline \multicolumn{8}{|l|}{ Hospital location } \\
\hline Ambo* & $99(45.6)$ & - & - & - & - & - & 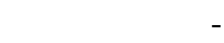 \\
\hline Gindeberet & $69(31.8)$ & -.54 & .13 & -.25 & .000 & -.80 & -.27 \\
\hline \multicolumn{8}{|l|}{ Allowances } \\
\hline No allowances * & $156(71.9)$ & - & - & - & - & - & - \\
\hline$>=1000 \mathrm{ETB}$ & $15(6.9)$ & .83 & .22 & .21 & .000 & .39 & 1.27 \\
\hline 500-999ЕТВ & $18(8.3)$ & .49 & .21 & .14 & .023 & .07 & .91 \\
\hline 150-499ETB & $28(12.9)$ & .33 & .16 & .11 & .044 & .01 & .65 \\
\hline
\end{tabular}

Dependent Variable: work motivation *Reference categories (category with highest frequencies). $\mathrm{F}=$ frequencies 


\section{DISCUSSION}

This study showed that there is no statistically significant relationship between sociodemographic variables (age, sex, ethnicity, marital status, religion) and their motivation. This finding is different from a study conducted on motivation and job satisfaction among medical and nursing staff in a Cyprus, public Nicosia General Hospital which revealed the female doctors reported being motivated significantly by remuneration (salary, benefits, pension and vacation schemes) than their male counterparts (15). This difference may be due to the difference in socio-political system between the study areas. It is also different from a study conducted in Addis Ababa hospitals which revealed that nurses' motivation depended on age (16). The difference may be related to inclusion of only nursing health professionals in the study carried out in Addis Ababa.

Motivation level of hospital health professionals differs from hospital to hospital. Health professionals from Ambo Hospital scored higher mean motivation score than Gindeberet Hospital health professionals. This may be because of the difference in distance from the central and zonal capital town. These hospitals also differ in the infrastructures they have like road, water supply, electricity, access to transportation services, etc. For example, Ambo Hospital is found in the zonal town and at a distance of only $114 \mathrm{kms}$ from Addis Ababa, the capital city of Ethiopia, with full access to transportation. However, Gindeberet Hospital is found at a distance of $195 \mathrm{kms}$ from Addis Ababa, and there is sever difficulty in access to transportation services. Gindeberet Hospital being in the district town, health professionals do not almost have access to cafes, restaurants, recreation centers, centers for further education for health professionals, etc. At the same time, monthly allowances and monthly top-ups given to health professionals at Gindeberet Hospital were relatively higher than the other two hospitals. Educational opportunities were also more available for health professionals working in Gindeberet Hospital than for those working in Ambo or Gedo hospitals. The availability of different materials like lap-tops was more in Gindeberet Hospitals than in the other two hospitals. Even, there was DSTV service in the hospital compound of Gindeberet Hospital, which was not available in the other two hospitals for health professionals. An indepth interview participant also supported this idea saying, "But this people according to our district, for example, water supply and electricity services will be interrupted frequently; they do not obtain transportation services when they need it, there is absolutely no recreation center which disappoints them" (39 years old, CEO). In Ethiopia, motivation is affected by non-conducive working environment, shortage of staff housing and transport facilities for health professionals to stay in remote areas (17).

Health professionals earning monthly financial benefits had higher motivation score when compared with health professionals who did not obtain any financial benefits. In-depth interview participants supported this idea as: "Health professionals who obtain incentives are more motivated than those who do not obtain incentives." (27 years old, clinical director); "But there is something that these health professionals need, meaning additional things that motivate them. For example nurses are obtaining 35.00 ETB duties. They need this duty to be increased. There is also a question for salary increase."(26 years old, clinical director). A finding from health worker (internal customer) satisfaction and motivation in the public sector in Ghana shows low salary was the most frequently mentioned de-motivator for over $94 \%$ of staff in all districts (18).

Qualification of health professionals was associated with their motivation. A report from a study conducted on employee motivation and performance in the healthcare industry in the Middle East supports this finding in which motivation had positive and significant relationships with education (qualification) (12). The study conducted in Addis Ababa hospitals on the relationship between rewards and nurses' motivation reported that there was a significant relationship between motivation and educational qualification of nurses (16).

On the other hand, job content related factors affect motivation and include knowledge of what is expected to be achieved, relationship of colleagues, doing challenging 
work and training opportunities. This finding was also consistent with findings from Peter et al in a study conducted on public and private sector health workers in Andhra Pradesh and Uttar Pradesh, India, which found that the three of the top five job characteristics for motivation with the highest important rating overall were "good working relationships with colleagues", "training opportunities" and "challenging work" all of which were included in the "job content' component (11).

West Shoa hospital health professionals overall motivation score was $63.63 \%$ calculated as percentage of maximum scale score. All the in-depth interview participants rated their respective health professionals' motivation as "medium." A study from public health facilities in Malawi shows that mean level scores of intrinsic motivation of health workers range from motivated to highly motivated to fulfill their jobs (13). A report from assessment of the role of non-financial incentives for motivation in Kenya shows that more than $55 \%$ of health workers do not place their own level of motivation in the category "rather good," "high" or "very high." Only around a quarter $(26.83 \%)$ of health professionals assessed their level of motivation as "very high," "high" or "rather good" from public services in Benin (19).

In conclusion, motivation of health professionals was affected by different factors: supervisor related factors, financial benefits, job content, professional qualification and location of the hospital. A significant proportion of participants believed that the current supervision positively impacted their motivation. Health professionals working in Ambo Hospital, which is geographically favored with better social infrastructures, were more motivated than their counterparts working in Gindeberet Hospital. The mean motivation score of health professionals who did not get any monthly financial benefit was significantly lower than those who did. Doctors responded that their job content had higher impact in their motivation while nurse responded it had a lesser impact in their motivation. It is therefore recommended that achievements and good work by health professionals should be recognized by their respective hospitals through creating reward and recognition systems. The hospitals need to devise ways of accessing financial benefits to those health professionals who do not get any financial benefits based on their performance. Gindeberet Hospital should collaborate with relevant sectors like road and transportation authority to improve health professionals' access to transportation services. The works achieved by health professionals should be properly communicated, and relationship among them needs to be enhanced. Training opportunities should be created to facilitate health professionals' career developments. The main limitation of the study was that the questionnaire was administered to the participants while they were on their routine duty that they may have responded to the items without deep understanding them. All types of Health professionals' category was also not equally represented in the study.

\section{REFERENCES}

1. Bennett S, and Franco LM, Public Sector Health Worker Motivation and Health Sector Reform: A Conceptual Framework. Major Applied Research 5, Technical Paper 1. Bethesda, MD: Partnerships for Health Reform Project, Abt Associates Inc. January 1999.

2. Bennett S, and Franco LM, Health Worker Motivation and Health Sector. Reform Primer for policy makers. Partnership for health reform. 2000.

3. Dieleman M, and Harnmeijer JW, Improving health worker performance: in search of promising practices. World Health Organization. KIT - Royal Tropical institute The Netherlands. September 2006.

4. Global Health Workforce Alliance. Guidelines: Incentives for Health Professionals. Prepublication Copy. 2008

5. World Health Organization: Workshop on global health workforce strategy Annecy, France. Geneva 2001

6. Human Resources for Health Country Profile Ethiopia. Africa Health Workforce Observatory. June 2010 p: 10

7. Dejene T, Health Situation in Ethiopia, German Ethiopian Association. Ausgabe, November 2003

8. Girma S, et al, Human Resource Development for Health in Ethiopia: Challenges of Achieving the Millennium development Goals. Ethiop.J.Health Dev. 2007; 21 
(3):216-231

9. Lindelow M, Serneels $\mathrm{P}$ and Lemma T, The Performance of Health Workers in Ethiopia Results from Qualitative Research. World Bank Policy Research Working Paper 3558, April 2005

10. Malik AA, et al. Motivational determinants among physicians in Lahore, Pakistan. BMCHealthServices Research 2010, 10:201

11. Peters DH, et al, Job satisfaction and motivation of health workers in public and private sectors: cross-sectional analysis from two Indian states. Human Resources for Health 2010, 8:27

12. Suliman AM, and Al-Sabri N, Surviving Through the Global Downturn: Employee motivation and Performance in Healthcare Industry. The Open Business Journal, 2009, 2, 86-94

13. Goldberg, Allison B, and Levey IR, Understanding the Complex Drivers of Intrinsic Motivationfor Health Workers in Malawi. Bethesda, MD: Health Systems 20/20 project, Abt Associates Inc. May 2012.

14. Mollahalğloğlu S, Kosdak M and Tag̈kaya S,
Healthcare employee satisfaction survey. Republic of Turkey, Ministry of Health. Ankara 2010

15. Lambrou P., Kontodimopoulos N. and Niakas Dimitris: Motivation and job satisfaction among medical and nursing staff in a Cyprus public general hospital. Human Resources for Health. 2010 8:26

16. Negussie N, Relationship between Rewards and Nurses' Work Motivation in Addis Ababa Hospitals. Ethiop JHealth Sci. July 2012, 22:2

17. Ethiopian Federal Ministry of Health: Health Sector Strategic Plan (HSDP-III) 2005/62009/10. Planning and Programming Department. 2005

18. Agyepong IA, et al, Health worker (internal customer) satisfaction and motivation in the public sector in Ghana. Int JHealth Plann Mgmt 2004; 19: 319-336

19. Mathauer I, Imhoff I, Health worker motivation in Africa: the role of non-financial incentives and human resource management tools. Hum. Resour. Health. Aug 2006 29;4:24. 